Original Research Paper

\title{
Analyzing the Role of Computerized Accounting Usefulness with Quantile Regression
}

\author{
Quang Linh Huynh \\ School of Economics and Law, Tra Vinh University, \\ No. 126 National Road 53, Ward 5, Tra Vinh City, Vietnam
}

Article history

Received: 05-09-2015

Revised: 03-10-2015

Accepted: 13-10-2015

Email: huynhquanglinh @tvu.edu.vn

\begin{abstract}
Previous research has examined the determinants resulting in the implementation of computerized accounting, mainly relying on the Generalized Linear Model (GLM), based on the conditional mean of dependent variables. The aim of this document is to analyze the implementation of computerized accounting systems with the quantile regression. Additionally, it attempts to study the mediating role of the perceived usefulness of computerized accounting in the implementation of computerized accounting systems as well as to discover the moderating role of environmental factors and organizational factors. The findings reveal that the effects of factors on the perceived usefulness of computerized accounting systems and on the implementation of these systems vary according to quantile levels. The perception of computerized accounting usefulness plays the mediating role in the implementation of computerized accounting systems. Only organizational factors, not environmental factors, moderate the relationship between the perceived usefulness of computerized accounting systems and the implementation of these systems.
\end{abstract}

Keywords: Quantile Regression, Computerized Accounting Usefulness, Environmental Factor, Organizational Factor

\section{Introduction}

Computerized accounting refers to the computerization of accounting information and tasks to help managers in making good business decisions. Hence, the implementation of computerized accounting systems plays a decisive role in creating success for a firm. The perspective is similar to those of (Chan et al., 2004; Tudisca et al., 2014). While Chan et al. (2004) suggest the implementation of human resource practices leading to improving firm performance, Tudisca $e t$ al. (2014) emphasize that the adoption of entrepreneurial strategies in business will enhance competitive advantages for the firm. In addition, several scholars have performed studies on the adoption of tools relevant to internet or computer such as Al-Nasser et al. (2014); whereas different researchers have investigated the predictors of the implementation of computerized accounting systems in business (Breen et al., 2003; Sam et al., 2012; Wang and Huynh, 2013; Huynh and Lin, 2013). Those studies analyze the relationships mainly relying on the Generalized Linear Model (GLM), which estimates the effect of the determinants on the conditional mean of computerized accounting implementation. Although estimating how 'on average' the factors affect the implementation of computerized accounting systems in business yields straightforward interpretations, this standard procedure may ignore various affecting levels at different points of the conditional distribution of computerized accounting adopting levels. Therefore, it is necessary to examine the relationships among the implementation of computerized accounting systems and its determinants with the quantile regression. This technique is to evaluate various affecting levels at different points of the conditional distribution. Furthermore, implied from Baron and Kenny (1986), the perception of computerized accounting usefulness is an important variable, which is deemed to play a crucial mediating role in the relationships between the implementation of computerized accounting systems and its determinants. Nonetheless, no research has so far studied the determinants of the perception of computerized accounting usefulness as well as the mediating role of the perception of computerized accounting usefulness in the relationships between the implementation of 
computerized accounting systems and its determinants. This paper tries to explore the factors affecting the perception of computerized accounting usefulness as well as the role of the perceived usefulness of computerized accounting systems in the implementation of computerized accounting systems. Overall, this paper examines the role of the determinants in the perceived usefulness of computerized accounting systems and the implementation of those tools with the quantile regression. Further, it applies the procedure offered by Sobel (1982) to examine the mediating role of the perception of computerized accounting usefulness in the associations between the implementation of computerized accounting systems in business and its determinants.

\section{Literature Review}

The implementation of computerized accounting systems is determined based on the research by Wang and Huynh (2013). They define the implementation of computerized accounting systems as the extent to which a firm adopts and implements computers and the internet for accounting work. That research also implies that mangers at various firms perceive the usefulness of computerized accounting systems differently depending on their firm conditions. Users' perceived usefulness of a tool is introduced by Davis (1989) in his research model. That model suggests the perceived usefulness of a tool as the degree to which a user thinks that using a particular tool will advance their performance. Taking these perspectives, this research regards the perceived usefulness of computerized accounting systems as the extent to which managers believe these systems as useful in improving their firm performance. The findings from Iacovou et al. (1995) reveal that firms, which perceive the usefulness of the electronic data tool, will more likely adopt this tool in business. Moreover, Pare et al. (2006) also affirm the relationship between the perceived usefulness of information system and the implementation of this system. Investigating the usage of business management software, Hernandez et al. (2008) discover that the perceived usefulness of business management software imposes positive effect on the implementation of this software. Additionally, the perceived usefulness is considered to play an important role in the implementation of management software in business (Nitaya et al., 2010). The above arguments are consistent with Davis (1989), in which a user's perceived usefulness of a tool may stimulate them to adopt it to enhance their performance. Similarly, Alrawabdeh et al. (2015) in their study "Factors Affecting the Implementation of the National Program for Information Technology in the National Health Services" also ascertain that users who perceive a system as useful will adopt and use this system. Furthermore, following the research by Gullkvist (2003) on the effect of the perceived usefulness on the adoption of computerized accounting systems, Sam et al. (2012) and Wang and Huynh (2013) provide evidence on the relationships between the perceived usefulness of computerized accounting systems and the implementation of these techniques. Computerized accounting systems function similarly to the above mentioned tools, in which they are all aimed to enhance business performance. Therefore, these arguments lead me to believe that managers, who regard computerized accounting systems as useful to their firms, will implement them in business in order to improve firm performance. Hence, the following hypothesis can be arrived at:

H1: Perceived usefulness affects the implementation of computerized accounting systems in business

With respect to business environment, Milliken (1987) specifies environmental factors as difficulty that managers have in predicting their business environment, since they have a little information to exactly forecast business situations. In addition, Miller (1993) classifies environmental factors into six areas. In agreement with Miller (1993), in this research, the environmental variable is defined as (1) governmental policies, (2) economy, (3) resources and services used by the company, (4) product market and demand, (5) competition and (6) technology. In regard to the link between the perceived usefulness of management tools and environmental uncertainty, Chenhall and Morris (1986) show that the usefulness of management tools perceived by managers is significantly related to environmental uncertainty facing them. Furthermore, as for management information system, Mangaliso (1995) proves the relationship between the perceived usefulness of management information system and the contextual variable of environmental uncertainty. A few years later, Fisher (1995) indicates that the association between the environmental uncertainty and the perceived usefulness of management information system is established. Moreover, Wright and Ashill (1998) reveal that environmental uncertainty increases the perceived usefulness of management information. This finding is also supported by Ashill and Jobber (2010) who find out the impact of environmental uncertainty on the perceived usefulness of management information system. These arguments are matching with the perspective of Davis (1989), in which external variables can predict a user's perceived usefulness of the tools they will apply for their processes. These discussions can be used to explain for the computerized accounting setting, because computerized accounting systems are also aimed at better control. Hence, the supposition that managers' perceived usefulness of computerized accounting systems is explained by environmental factors can be come to. 
In studies on management tools, Waterhouse and Tiessen (1978) and Fisher (1995) propose that there is no management tool that is "the best" for all kinds of firms and maintain that the context facing the firm will determine which management systems are suitable to that firm. In addition, Gordon and Miller (1976) confirm that if there is an increase in the environmental uncertainty, a firm finds it more essential to adopt management tools. Likewise, Horngren (1982) discovers that the external environment where the firm operates will predict the implementation of control tools in business. Furthermore, Wierenga and Ophuis (1997), in the research on management information systems, suggest that environmental factors may affect the implementation of management information systems in business; while Iacovou et al. (1995), who conducts the research on electronic data system, reveals that environmental factors put an impact on electronic data system adopted by organizations. Moreover, Haldma and Lääts (2002) claim that external factors impact on the implementation of management system. Similarly, Ajibolade et al. (2010) and Ibadin and Imoisili (2010) assert that there is a relationship between environmental uncertainty and the design of management system. Environmental uncertainty is also discovered by (Sam et al., 2012; Wang and Huynh, 2013; Huynh and Lin, 2013) as a driving force of the implementation of computerized accounting systems in business. Adapting these findings to the computerized accounting context allows me to theorize the following hypotheses:

$\mathrm{H} 2 \mathrm{a}$ : Firms in a more uncertain environment are more likely to perceive computerized accounting systems as useful to their business.

$\mathrm{H} 2 \mathrm{~b}$ : Firms in a more uncertain environment are more likely to implement computerized accounting systems in business.

Implied from Chen and Huang (2007), organizational factors refer to (1) decentralization, (2) mutual adjustment, (3) integration, (4) trust, (5) communication and (6) coordination. In this research, the organizational factors are specified similar to those from Chen and Huang (2007), consisting of the six above mentioned dimensions. In evaluation of the role of individual and organizational factors in explaining level of technology acceptance, Lee et al. (2009) propose that organizational characteristics serve as a driver of users' perceived usefulness of a new management system. On the other hand, Wierenga and Ophuis (1997) suggest that organizational factors influence managers' decisions of adopting management information systems in business. Similarly, a research by Haldma and Lääts (2002) argues that organizational factors are the determinants of the use of the control system. Furthermore, Mellahi and Eyuboglu (2001) suggest that organizational characteristics are critical factors for the implementation of quality management system. Likewise, Warwood and Roberts (2004) also emphasize that organizational characteristics play an important role in the implementation of quality management system in business. Following them, Abdel-Kader and Luther (2008) ascertain the impact of organizational factors on the implementation of management systems, whereas Masrek (2009) indicates organizational factors explain the utilization of information systems in a firm. A year later, Nitaya et al. (2010) discover that the implementation of accounting programs is affected by organizational characteristics. Further, Wang and Huynh (2013) find out the link between organizational characteristics and the implementation of computerized accounting systems in business. These findings enable me to posit the following hypotheses for the computerized accounting context:

H3a: Organizational factors has impact on the perceived usefulness of computerized accounting systems in business

$\mathrm{H} 3 \mathrm{~b}$ : Organizational factors affect the implementation of computerized accounting systems in business

So far, this research has argued that environmental and organizational factors play an essential role in managers' perception of computerized accounting usefulness, which in turn leads to the implementation of computerized accounting systems in business. These variables have been investigated in simple bivariate relationships. Nevertheless, the relationships among these variables are more complex. Baron and Kenny (1986) claim that the relationship between an explanatory variable and an explained variable is often modified by the addition of an intermediary variable into the research model. They offer a procedure to examine the intermediary influence on the link between the explanatory variable and the explained variable. Three conditions are necessarily satisfied for the existence of the mediating effect. Firstly, an explanatory variable significantly affects an explained variable. Secondly, the explanatory variable also significantly impacts on an intermediary variable. Thirdly, the intermediary variable, in turn, predicts the explained variable. The satisfaction of the three conditions will suggest that the intermediary variable mediates the association between the explanatory variable and the explained variable. In addition, Sobel (1982) introduces a method to examine the statistical significance for the mediating effect by testing the null hypothesis that states the indirect effect of the explanatory variable on the explained variable through the mediating variable is not occurred. 


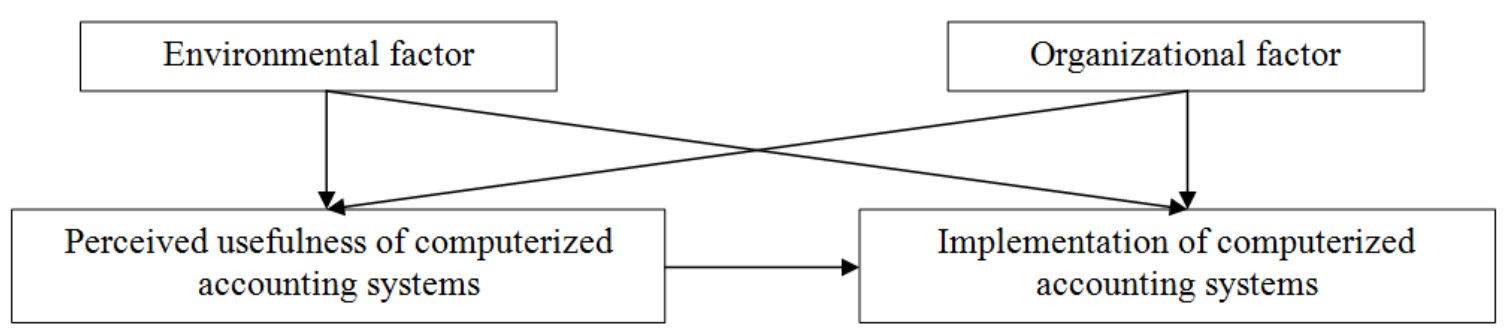

Fig. 1. Research model

Grounded on the suggestions by Baron and Kenny (1986), the above hypotheses lead to the following mediating hypotheses:

H4a: Perceived usefulness mediates the effect of environmental factors on the implementation of computerized accounting systems.

H4b: Perceived usefulness mediates the effect of organizational factors on the implementation of computerized accounting systems.

\section{Research Model}

The above hypotheses help to create a proposed research model as illustrated in Fig. 1. After arriving at the research model, the research methodology will be introduced to guide the data collection and facilitate the statistical analysis in the subsequent part.

\section{Methodology}

\section{Variable Measurement}

There are four variables used in this study, which are the implementation of computerized accounting systems, the perceived usefulness of computerized accounting systems, environmental factor and organizational factors. These four variables are employed and measured as follows.

Implementation of Computerized Accounting Systems (ICAS) is measured with a five-point scale ranging from 1.never considering, 2.decided not to introduce, 3.favored to introduce, 4.intended to introduce, to 5.under implementation of computerized accounting systems, which are (1) the usage of computer for accounting workICAS1, (2) the usage of accounting software- ICAS2, (3) the usage of internet-accounting within the companyICAS3, (4) the usage of internet-accounting with other outside agencies- ICAS4 and (5) the usage of internetaccounting for other purposes- ICAS5, adapted from Huynh and Lin (2013). Perceived Usefulness of Computerized Accounting Systems (UCAS) is measured with the five items corresponding to the five items of "Implementation of Computerized Accounting Systems". A five-point scale is employed ranging from the implementation of computerized accounting system being 1.not at all useful, 2.a little useful, 3.quite useful, 4.useful and to 5.very useful for business, adapted from Hyvonen (2005) and Al-Omiri and Drury (2007).

Environmental Factor (ENF) is measured with a fivepoint scale ranging from 1.always predicted, 2.easily predicted, 3.difficult to be predicted, 4.quite difficult to be predicted to 5.very difficult to be predicted for the six dimensions: (1) government policies- ENF1, (2) economy-ENF2, (3) competition- ENF3, (4) product market and demand- ENF4, (5) resources and services used by the company- ENF5 and (6) technology- ENF6, adapted from Miller (1993). Organizational Factor (ORF) is measured with six dimensions, which are (1) decentralization-ORF1, (2) mutual adjustment-ORF2, (3) integration-ORF3, (4) trust-ORF4, (5) communication-ORF5 and (6) coordination-ORF6. A five-point scale is used to assess the three first dimensions; namely (1) decentralization ranging from 1.centralizing decision-making power to 5.decentralizing decision-making power, (2) mutual adjustment ranging from 1.formalized to 5.informalized and (3) integration ranging from 1.no integration to 5.integration. The three last dimensions are measured by using a five-point scale ranging from 1.never occurred to 5.always occurred. The types and scales are adapted and slightly modified from Chen and Huang (2007).

\section{Collection and Analysis of the Data}

The 686 firms publicly listed on Vietnamese Stock Exchanges (376 on Ha Noi Stock Exchange and the other 310 on Ho Chi Minh Stock Exchange) were taken into account for this research. The questionnaire was conducted with a manager involved in management accounting for each targeted firm. The 686 questionnaires were sent to 686 firms by email. However, lastly only 328 replies provide sufficiently required information for this research. Before doing further analyses, the reliability and factor analyses are undertaken to test the properties of measurement scales and assess the construct validity. Then, the quantile regression is applied to investigate our causal relationships. The method introduced by Sobel (1982) is used to explore the mediating relationships. Finally, the interactive terms are utilized to explore the moderating relationships. 


\section{Results}

To test the reliability and construct validity of the data, the reliability and factor analyses are undertaken. The results of reliability and factor analyses are presented in Table 1 and 2. The dimension "ENF6technology" of "ENF-Environmental Factor" is removed out of the data, since its item-total correlation of 0.334 is under 0.5 , the preferable level suggested by Nunnally (1978). The Cronbach's alphas for the four factors (ENFEnvironmental Factor, ORF-Organizational Factor, UCAS-Perceived Usefulness of Computerized Accounting Systems, ICAS-Implementation of Computerized Accounting Systems) after the deletion of ENF6 all exceed 0.7, the smallest level stipulated by Nunnally (1978). Table 2 only shows the factor-loadings of over 0.35 . The 21 communalities are all greater than 0.5 , the lowest limit by Hair et al. (2009). The crossloadings all exceed 0.3 and the factor-loadings are all more than 0.4 , the smallest limits suggested by Nunnally (1978). The Kaiser-Meyer-Olkin Measures of Sampling Adequacy (KMOs) are all over 0.7, the minimum value recommended by Hair et al. (2009). These results imply that our data achieves the construct validity and reliability. Consequently, the 21 retained items are all appropriate for further analyses. Before doing other analyses, the main factors (Environmental Factor-ENF, ORF-Organizational Factor, UCAS-Perceived
Usefulness of Computerized Accounting Systems and ICAS-Implementation of Computerized Accounting Systems) are computed by averaging their own retained items (5 items for ENF, UCAS and ICAS each and 6 items for ORF).

Previous papers analyze the determinants of the implementation of computerized accounting systems, mainly relying on the Generalized Linear Model (GLM), which estimates the effect of the determinants on the conditional mean of the implementation of computerized accounting systems. While estimating how 'on average' the factors affect the implementation of computerized accounting systems in business yields straightforward interpretations, this standard method may ignore the different affecting levels at different points of the conditional distribution of the implementation levels of computerized accounting systems. The relationships among the implementation of computerized accounting systems and their determinants are investigated with the quantile regression, which analyzes different affecting levels at different points of the conditional distribution, in comparison with the OLS regression. The results are shown in Table 3. The quantile regression is also employed in contrast with the OLS regression to examine the predictors of the perceived usefulness of computerized accounting systems, which produce the outcomes in Table 4.

Table 1 . Reliability analysis

\begin{tabular}{llllll}
\hline Factor & $\begin{array}{l}\text { No. of items } \\
\text { before deletion }\end{array}$ & $\begin{array}{l}\text { Item } \\
\text { deleted }\end{array}$ & $\begin{array}{l}\text { Item-total } \\
\text { correlation deleted }\end{array}$ & $\begin{array}{l}\text { Cronbach's } \\
\text { alpha }\end{array}$ & $\begin{array}{l}\text { No. of items } \\
\text { retained }\end{array}$ \\
\hline ENF & 6 & ENF6 & 0.334 & 0.882 & 5 \\
ORF & 6 & & & 0.889 & 6 \\
UCAS & 5 & & & 0.838 & 5 \\
ICAS & 5 & & 0.850 & 5 \\
\hline
\end{tabular}

Table 2. Factor analysis

\begin{tabular}{|c|c|c|c|c|c|c|}
\hline \multirow[b]{2}{*}{ Item } & \multicolumn{4}{|l|}{ Factor } & \multirow[b]{2}{*}{ Communalities } & \multirow[b]{2}{*}{ KMO } \\
\hline & 1 & 2 & 3 & 4 & & \\
\hline ENF1 & & & 0.708 & & 0.694 & 0.875 \\
\hline ENF2 & & & 0.734 & & 0.737 & \\
\hline ENF3 & & & 0.799 & & 0.696 & \\
\hline ENF4 & & & 0.691 & & 0.659 & \\
\hline ENF5 & & & 0.758 & & 0.684 & \\
\hline ORF1 & 0.775 & & & & 0.672 & 0.879 \\
\hline ORF2 & 0.746 & & & & 0.617 & \\
\hline ORF3 & 0.822 & & & & 0.697 & \\
\hline ORF4 & 0.811 & & & & 0.704 & \\
\hline ORF5 & 0.765 & & & & 0.623 & \\
\hline ORF6 & 0.793 & & & & 0.652 & \\
\hline UCAS1 & & & & 0.784 & 0.637 & 0.781 \\
\hline UCAS2 & & & & 0.662 & 0.595 & \\
\hline UCAS3 & & & & 0.716 & 0.568 & \\
\hline UCAS4 & & & & 0.769 & 0.696 & \\
\hline UCAS5 & & & & 0.717 & 0.602 & \\
\hline ICAS1 & & 0.697 & & & 0.618 & 0.828 \\
\hline ICAS2 & & 0.686 & & & 0.608 & \\
\hline ICAS3 & & 0.759 & & & 0.624 & \\
\hline ICAS4 & & 0.771 & & & 0.665 & \\
\hline ICAS5 & & 0.748 & & & 0.636 & \\
\hline
\end{tabular}


Table 3. Comparison of OLS and quantile regression results with ICAS as the dependent variable

\begin{tabular}{|c|c|c|c|c|c|c|}
\hline \multirow{2}{*}{$\begin{array}{l}\text { Independent } \\
\text { variable }\end{array}$} & \multirow[b]{2}{*}{ OLS } & \multicolumn{5}{|l|}{ Quantile } \\
\hline & & 0.10 & 0.25 & 0.50 & 0.75 & 0.90 \\
\hline$\overline{\mathrm{ENF}}$ & $0.4667 * * *$ & $0.5581 * * *$ & $0.4871^{* * * *}$ & $0.4667 * * *$ & $0.5161 * * *$ & $0.4726^{* * * *}$ \\
\hline ORF & $0.1181 * *$ & $0.2791 * * *$ & $0.1316^{*}$ & $0.1120 * *$ & $0.0774^{*}$ & 0.0146 \\
\hline UCAS & $0.1737 * * *$ & -0.0203 & 0.1145 & $0.2133 * * *$ & $0.2258 * * *$ & $0.2409 * * *$ \\
\hline Constant & $0.7732 * * *$ & $-0.0145^{* *}$ & $0.5761 *$ & $0.6667 * *$ & $0.8903^{* * *}$ & $1.4854 * * *$ \\
\hline (Pseudo) R ${ }^{2}$ & 0.4025 & 0.2600 & 0.2325 & 0.2660 & 0.2495 & 0.2381 \\
\hline
\end{tabular}

Table 4. Comparison of OLS and quantile regression results with UCAS as the dependent variable

\begin{tabular}{|c|c|c|c|c|c|c|}
\hline \multirow{2}{*}{$\begin{array}{l}\text { Independent } \\
\text { variable }\end{array}$} & \multirow[b]{2}{*}{ OLS } & \multicolumn{5}{|l|}{ Quantile } \\
\hline & & 0.10 & 0.25 & 0.50 & 0.75 & 0.90 \\
\hline$\overline{\text { ENF }}$ & $0.4149 * * *$ & $0.52 * * *$ & $0.5434 * * *$ & $0.4531 * * *$ & $0.3461 * * *$ & $0.2500^{* * *}$ \\
\hline ORF & $0.1223 * * *$ & $0.192 *$ & $0.1957 * *$ & $0.15^{* * *}$ & 0.0462 & -0.0000 \\
\hline Constant & $2.1069 * * *$ & $0.6959 *$ & $1.0348 * * *$ & $1.9250 * * *$ & $3.0769 * * *$ & $3.8000 * * *$ \\
\hline (Pseudo) $\mathrm{R}^{2}$ & 0.3179 & 0.1898 & 0.2017 & 0.2043 & 0.1185 & 0.1105 \\
\hline
\end{tabular}

The findings from the quantile regression indicate some essential differences across different points in the conditional distribution of changes in the implementation of computerized accounting systems as well as in the perceived usefulness of computerized accounting systems. The results in Table 3 reveal that, with the OLS regression, environmental factors and organizational factors as well as the perceived usefulness of computerized accounting systems positively influence the implementation of computerized accounting systems at the $0.01,0.05$ and 0.01 significance levels respectively, which is similar to the results obtained from the 0.50 quantile regression. This implies that the hypotheses $\mathrm{H} 1, \mathrm{H} 2 \mathrm{~b}$ and $\mathrm{H} 3 \mathrm{~b}$, that the perceived usefulness of computerized accounting systems, environmental factors and organizational factors are related to the implementation of computerized accounting systems, are statistically supported. However, differences can be seen across different points in the conditional distribution of the implementation of computerized accounting systems. At the higher side of the conditional distribution of the implementation of computerized accounting systems, the relationship between organizational factors and the implementation of computerized accounting systems is statistically insignificant (at the 0.90 quantile). In contrast, at the $0.75,0.50,0.25$ and 0.10 quantiles, organizational factors put statistically significant effect on the implementation of computerized accounting systems. The results are converse for the perceived usefulness of computerized accounting systems, which is insignificantly connected with the implementation of computerized accounting systems at the lower side of the conditional distribution (the 0.10 and 0.25 quantiles); whereas this relationship is statistically significant at the higher quantiles $(0.50,0.75$ and 0.90$)$. Differently from the two other explained constructs, environmental factors impose statistically significant effect on the implementation of computerized accounting systems at any quantiles at the 0.01 significance level with the coefficients fluctuating around the 0.5 value. Overall, environmental factors play the most important role in predicting the implementation of computerized accounting systems; while organizational factors are least important.

The findings shown in Table 4 demonstrates that environmental factors and organizational factors are statistically associated with the perceived usefulness of computerized accounting systems at the 0.50 quantile as well as OLS at the 0.01 significance level, which provides statistical evidence on the hypotheses $\mathrm{H} 2 \mathrm{a}$ and $\mathrm{H} 3 \mathrm{a}$, that environmental factors and organizational factors affect the perceived usefulness of computerized accounting systems. Nonetheless, Table 4 also shows different results across the different quantiles. While environmental factors statistically affect the perceived usefulness of computerized accounting systems at any quantiles; the relationship between organizational factors and the perceived usefulness of computerized accounting systems is only statistically significant at the lower side of the conditional distribution (the $0.10,0.25$ and 0.50 quantiles), but insignificant at the higher side of the conditional distribution (the 0.75 and 0.90 quantiles). Generally speaking, environmental factors are more important than organizational factors in explaining the perceived usefulness of computerized accounting systems as well as the implementation of computerized accounting systems. Having provided statistical evidence on the causal relationships among environmental factors, organizational factors, the perceived usefulness of computerized accounting systems and the implementation of these systems, I now try to examine the mediating role of the perceived usefulness of computerized accounting systems in the influences of environmental factors and organizational factors on the implementation of computerized accounting systems. 
The outcomes in Table 5 indicate that environmental factors and organizational factors both statistically influence the implementation of computerized accounting systems as well as the perceived usefulness of computerized accounting systems that in turn leads to the implementation of computerized accounting systems. Furthermore, the addition of the perceived usefulness of computerized accounting systems causes a reduction in the effects of environmental factors and organizational factors on the implementation of computerized accounting systems from the coefficients of 0.585 and 0.331 down to 0.494 and 0.210 respectively. In concurrence with Baron and Kenny (1986), these findings allow me to believe that the perceived usefulness of computerized accounting systems intervene in the influences of environmental factors and organizational factors on the implementation of computerized accounting systems.

Then, a technique proposed by Sobel (1982) is employed to test the statistical significance for these intervenient associations. Table 6 reveals that the effects of environmental factors and organizational factors on the implementation of computerized accounting systems are statistically affected by the perceived usefulness of computerized accounting systems at the 0.01 significance level. Hence, the hypotheses H4a and H4b, that the perceived usefulness of computerized accounting systems mediates the effect of environmental factors and organizational factors on the implementation of computerized accounting systems, are statistically supported. The inclusion of the perceived usefulness of computerized accounting systems in the research model will reduce the effects of environmental factors and organizational factors on the implementation of computerized accounting systems.

The relationships among environmental factors, organizational factors, the perceived usefulness of computerized accounting systems and the implementation of these tools are more complex than expected bivariate ones. Environmental factors and organizational factors are discovered to affect both the perceived usefulness of computerized accounting systems and the implementation of computerized accounting systems. Accordingly, I can suggest that environmental factors and organizational factors may moderate the relationship between the perceived usefulness of computerized accounting systems and the implementation of those practices. The uncertainty of environment and the complication of organizational structure may increase or decrease the effect of the perceived usefulness of computerized accounting systems on the implementation of these systems. The interactive terms ENF*UCAS and ORF*UCAS are included to examine the moderating relationships, which yields the results in Table 7 and 8 . The findings in Table 7 offer evidence that the uncertainty of environment does not put statistically significant effect on the impact of the perceived usefulness of computerized accounting systems on the implementation of those systems at the 0.05 level and even not at the 0.1 level. However, Table 8 discovers that the complication of organizational structure statistically moderates the relationship between the perceived usefulness of computerized accounting systems and the implementation of these systems at the 0.05 significance level.

Table 5. Results from multiple regressions for mediating relationship

\begin{tabular}{llllll}
\hline Dependent variable & Independent variable & Coefficient & Std. Error & $t_{\text {stat }}$ & $P_{\text {value }}$ \\
\hline ICAS & ENF & 0.585 & 0.042 & 13.833 & 0.000 \\
ICAS & ORF & 0.331 & 0.052 & 6.3420 & 0.000 \\
ICAS & UCAS & 0.198 & 0.060 & 3.3100 & 0.001 \\
& ENF & 0.494 & 0.050 & 9.9350 & 0.000 \\
ICAS & UCAS & 0.448 & 0.059 & 7.6340 & 0.000 \\
& ORF & 0.210 & 0.051 & 4.1450 & 0.000 \\
UCAS & ENF & 0.455 & 0.039 & 11.822 & 0.000 \\
UCAS & ORF & 0.270 & 0.045 & 5.9440 & 0.000 \\
\hline
\end{tabular}

Table 6. Results of Sobel tests for mediating effect of UCAS

\begin{tabular}{lll}
\hline Relationship & $t_{\text {indirect }}$ & $P_{\text {value }}$ \\
\hline ENF and ICAS & 3.1775 & 0.000 \\
ORF and ICAS & 4.7077 & 0.000 \\
\hline
\end{tabular}

Table 7. Results from multiple regressions for moderating relationship

\begin{tabular}{lllllll}
\hline Dependent variable & Dependent variable & Coefficients & Std. Error & t & Sig. & Model-Fit \\
\hline \multirow{3}{*}{ (ICAS) } & (Constant) & 0.940 & 0.222 & 4.239 & 0.000 & 0.000 \\
& ENF & 0.494 & 0.050 & 9.935 & 0.000 & 0.001 \\
(ICAS) & UCAS & 0.198 & 0.060 & 3.310 & 0.022 & 0.000 \\
& (Constant) & 1.989 & 0.864 & 2.302 & 0.326 \\
& ENF & 0.220 & 0.224 & -0.350 & 0.727 \\
\\
& UCAS & -0.080 & 0.230 & 1.256 & 0.210 \\
\hline
\end{tabular}


Table 8. Results from multiple regressions for moderating relationship

\begin{tabular}{lllllll}
\hline Dependent variable & Dependent variable & Coefficients & Std. Error & $\mathrm{t}$ & Sig. & Model-Fit \\
\hline \multirow{3}{*}{ (ICAS) } & (Constant) & 1.220 & 0.252 & 4.847 & 0.000 & 0.000 \\
& ORF & 0.210 & 0.051 & 4.145 & 0.000 & \\
& UCAS & 0.448 & 0.059 & 7.634 & 0.000 & 0.612 \\
(ICAS) & (Constant) & -0.466 & 0.917 & -0.508 & 0.000 \\
& ORF & 0.771 & 0.298 & 2.589 & 0.000 & 0.050 \\
\hline
\end{tabular}

\section{Conclusion}

Prior papers have examined the predictors of the implementation of computerized accounting systems. They investigated the relationships mainly relying on the Generalized Linear Model (GLM), which estimates the effect of the determinants on the conditional mean of computerized accounting implementation. In addition, the perceived usefulness of computerized accounting systems is regarded as an important variable, which plays a decisive mediating role in the relationships between the implementation of computerized accounting systems and its determinants. However, no research has examined the determinants of the perceived usefulness of computerized accounting systems as well as the mediating role of the perception of computerized accounting usefulness in the relationships between the implementation of computerized accounting systems and its determinants. Furthermore, environmental factors and organizational factors may moderate the relationship between the perceived usefulness of computerized accounting systems and the implementation of those practices. These moderating effects have not been explored in previous research. This paper seeks to examine the relationships of the perceived usefulness of computerized accounting systems and the implementation of computerized accounting systems with their determinants with the quantile regression, which analyzes different affecting levels at different points of the conditional distribution. Then, it examines the mediating role of the perceived usefulness of computerized accounting usefulness in the associations between the implementation of computerized accounting systems and its determinants with Sobel's test. Finally, the interactive terms are used to investigate the moderating relationships.

This paper offers evidence that, on the conditional mean of the dependent variable with the OLS regression, environmental factors and organizational factors affect both the implementation of computerized accounting systems as well as both the perceived usefulness of computerized accounting systems, which in turn leads to the implementation of computerized accounting systems. With the quantile regression, organizational factors statistically influence the perceived usefulness of computerized accounting systems and the implementation of these systems at lower quantiles, but they do not at higher quantiles; while the effects of environmental factors on the perceived usefulness of computerized accounting systems and on the implementation of these systems are statistically significant at any quantiles. In contrast, the link between the perceived usefulness of computerized accounting systems and the implementation of these systems is statistically significant at higher quantiles, but is not at lower quantiles. This paper also discovers an important mediating role of the perceived usefulness of computerized accounting systems in the relationships among environmental factors, organizational factors and the implementation of computerized accounting systems. Furthermore, the author also find out that organizational factors moderate the association between the perceived usefulness of computerized accounting systems and the implementation of these systems. However, environmental factors do not affect this association.

To the literature, this paper is the first one to emphasize the importance of the perceived usefulness of computerized accounting systems and reveal that environmental factors and organizational factors statistically influence the perceived usefulness of computerized accounting systems, which in turn mediates the relationships among environmental factors, organizational factors and the implementation of computerized accounting systems. It is also the first to provide evidence on the moderating role of organizational factors in the relationship between the perceived usefulness of computerized accounting systems and the implementation of these systems. Furthermore, this paper provides the whole picture of the causal relationships with the quantile regression, suggesting that the causal relationships vary according to different quantile levels. To management, this paper provides managers with better understanding of the complex relationships among environmental factors, organizational factors, the perceived usefulness of computerized accounting systems and the implementation of these systems. These will help them in making better decisions on adopting computerized accounting systems in their organizations, so that they will attain the best possible performance for their business. 


\section{Acknowledgment}

I am sincerely grateful to my university, Tra Vinh University, for their partially financial support for this research and I also would like to thank the respondents for their effort and help in collecting the data for this research.

\section{Ethics}

This research is original and unpublished elsewhere. The author also confirms that there is no ethical issues involved.

\section{References}

Abdel-Kader, M.G. and R.G. Luther, 2008. The impact of firm characteristics on management accounting practices: A UK-based empirical analysis. Br. Account. Rev., 40: 2-27.

DOI: 10.1016/j.bar.2007.11.003

Ajibolade, S.O., S.S.A. Arowomole and R.K. Ojikutu, 2010. Management accounting systems, perceived environmental uncertainty and companies' performance in Nigeria. Int. J. Acad. Res., 2: 195-201.

Al-Nasser, M., R.Z. Yusoff, R. Islam and A. Al-Nasser, 2014. Effects of consumers' trust and attitude toward online shopping. Am. J. Econom. Bus. Administrat., 6: 58-71.

DOI: 10.3844 /ajebasp.2014.58.71

Al-Omiri, M. and C. Drury, 2007. A survey of factors influencing the choice of product costing systems in UK organizations. Manage. Account. Res., 18: 399-424. DOI: 10.1016/j.mar.2007.02.002

Alrawabdeh, W., A. Salloum and F. Shrafat, 2015. Factors affecting the implementation of the national programme for information technology in the national health services: The case of Lorenzo in the North, Midlands and East of England Region. Am. J. Applied Sci., 12: 20-30.

DOI: $10.3844 /$ ajassp.2015.20.30

Ashill, N.J. and D. Jobber, 2010. The impact of environmental uncertainty perceptions, decision-maker characteristics and work environment characteristics on the perceived usefulness of Marketing Information Systems (MkIS): A conceptual framework. J. Market. Manage., 15: 519-540. DOI: $10.1362 / 026725799785045815$

Baron, R.M. and D.A. Kenny, 1986. The moderatormediator variable distinction in social psychological research: Conceptual, strategic and statistical considerations. J. Personality Social Psychol., 51: 1173-1182. DOI: 10.1037/0022-3514.51.6.1173

Breen, J., N. Sciulli and C. Calvert, 2003. The use of computerised accounting systems in small business. Proceedings of the16th Annual Conference of Small Enterprise Association of Australia and New Zealand, 28 Sept. -1 Oct., Ballarat, Victoria, pp: 1-12.
Chan, L.L.M., M.A. Shaffer and E. Snape, 2004. In search of sustained competitive advantage: The impact of organizational culture, competitive strategy and human resource management practices on firm performance. Int. J. Hum. Resource Manage., 15: 17-35.

DOI: $10.1080 / 0958519032000157320$

Chen, C.J. and J.W. Huang, 2007. How organizational climate and structure affect knowledge management: The social interaction perspective. Int. J. Inform. Manage., 27: 104-118. DOI: 10.1016/j.ijinfomgt.2006.11.001

Chenhall, R.H. and D. Morris, 1986. The impact of structure, environment and interdependence on the perceived usefulness of management accounting systems. Account. Rev., 61: 16-35.

Davis, F.D., 1989. Perceived usefulness, perceived ease of use and user acceptance of information technology. Manag. Informat. Syst. Q., 13: 319-340. DOI: $10.2307 / 249008$

Fisher, J., 1995. Contingency-based research on management control systems: Categorization by level of complexity. J. Account. Literature, 14: 24-53.

Gordon, L.A. and D. Miller, 1976. A contingency framework for the design of accounting information systems. Account. Organ. Society, 1: 59-69.

DOI: 10.1016/0361-3682(76)90007-6

Gullkvist, B., 2003. Adoption and impact of eaccounting. Frontiers of E-Business Research.

Hair, J.F., W.C. Black, B.J. Babin, R.E. Anderson and R.L. Tatham, 2009. Multivariate Data Analysis. Pearson Prentice Hall, USA, New Jersey.

Haldma, T. and K. Laats, 2002. Contingencies influencing the management accounting practices of Estonian manufacturing companies. Manage. Account. Res., 13: 379-400. DOI: 10.1006/mare.2002.0197

Hernandez, B., J. Jimenez and M.J. Martın, 2008. Extending the technology acceptance model to include the IT decision-maker: A study of business management software. Technovation, 28: 112-121. DOI: 10.1016/j.technovation.2007.11.002

Horngren, C.T., 1982. Cost Accounting: A Managerial Emphasis. 5th Edn., Prentice-Hall, Englewood Cliffs, ISBN-10: 0131796305, pp: 252.

Huynh, Q.L. and Y.L. Lin, 2013. Mediation of Computerized Accounting System (CAS) adoption on relationship between environmental uncertainty and organizational performance. J. Modern Account. Audit., 9: 747-755.

Hyvonen, J., 2005. Adoption and benefits of management accounting systems: Evidence from Finland and Australia. Adv. Int. Account., 18: 97-120. DOI: $10.1016 / \mathrm{S} 0897-3660(05) 18005-2$ 
Iacovou, C.L., I. Benbasat and A.S. Dexter, 1995. Electronic data interchange and small organizations: Adoption and impact of technology. MIS Q., 19: 465-485. DOI: $10.2307 / 249629$

Ibadin, P.O. and O. Imoisili, 2010. Organization contexts and management accounting system design: Empirical evidence from Nigeria. Int. J. Current Res., 10: 064-073.

Lee, D., Y. Rhee and R.B. Dunham, 2009. The role of organizational and individual characteristics in technology acceptance. Int. J. Human-Comput. Interact., 25: 623-646. DOI: $10.1080 / 10447310902963969$

Mangaliso, M.P., 1995. The strategic usefulness of management information as perceived by middle managers. J. Manage., 21: 231-250. DOI: $10.1177 / 014920639502100204$

Masrek, M.N., 2009. Determinants of strategic utilization of information systems: A conceptual framework. J. Software, 4: 591-598. DOI: $10.4304 /$ jsw.4.6.591-598

Mellahi, K. and F. Eyuboglu, 2001. Critical factors for successful total quality management implementation in Turkey: Evidence from the banking sector. Total Quality Manage., 12: 745-756.

DOI: $10.1080 / 09544120120075352$

Miller, K.D., 1993. Industry and country effects on managers' perceptions of environmental uncertainties. J. Int. Bus. Studies, 24: 693-714.

DOI: $10.1057 /$ palgrave.jibs.8490251

Milliken, F.J., 1987. Three types of perceived uncertainty about the environment: State, effect and response uncertainty. Acad. Manage. Rev., 12: 133-143. DOI: $10.5465 / A M R .1987 .4306502$

Nitaya, W., K. Isada, R. Sirirat and C. Worachatr, 2010. Factors affecting adoption of GL module of oracle and SAP accounting programs. J. Bus. Administrat., 2: 38-52.
Nunnally, J.C., 1978. Psychometric Theory. McGrawHill, USA, New York.

Pare, G., C. Sicotte and H. Jacques, 2006. The effects of creating psychological ownership on physicians' acceptance of clinical information systems. J. Am. Med. Inform. Associat., 13: 197-205.

DOI: 10.1197/jamia.M1930

Sam, M.F.M., Y. Hoshino and M.N.H. Tahir, 2012. The adoption of computerized accounting system in small medium enterprises in Melaka, Malaysia. Int. J. Bus. Manage., 7: 13-25. DOI: $10.5539 /$ ijbm.v7n18p12

Sobel, M.E., 1982. Asymptotic confidence intervals for indirect effects in structural equation models. Sociological Methodol., 13: 290-312. DOI: $10.2307 / 270723$

Tudisca, S., A.M. Di Trapani, E. Donia, F. Sgroi and R. Testa, 2014. Entrepreneurial strategies of Etna wine farms. Int. J. Entrepreneurship Small Bus., 21: 155164.

Wang, D.H.M. and Q.L. Huynh, 2013. Effects of environmental uncertainty on computerized accounting system adoption and firm performance. Int. J. Humanit. Applied Sci., 2: 13-21.

Warwood, S. and P. Roberts, 2004. A survey of TQM success factors in the UK. Total Quality Manage. Bus. Excellence, 15: 1109-1117. DOI: $10.1080 / 1478336042000255460$

Waterhouse, J. and P. Tiessen, 1978. A contingency framework for management accounting systems research. Account. Organiz. Society, 3: 65-76. DOI: 10.1016/0361-3682(78)90007-7

Wierenga, B. and P.A.M.O. Ophuis, 1997. Marketing decision support systems: Adoption, use and satisfaction. Int. J. Res. Market., 14: 275-290. DOI: 10.1016/S0167-8116(97)00009-8

Wright, M. and N. Ashill, 1998. A contingency model of marketing information. Eur. J. Market., 32: 125-144. DOI: $10.1108 / 03090569810197525$ 